Research Article

\title{
Humification and Humic Acid Composition of Suspended Soil in Oligotrophous Environments in South Vietnam
}

\author{
E. V. Abakumov ${ }^{(D)}{ }^{1}$ O. A. Rodina, ${ }^{1}$ and A. K. Eskov ${ }^{2}$ \\ ${ }^{1}$ Saint-Petersburg State University, St.-Petersburg, Russia \\ ${ }^{2}$ Tsitsin Main Botanical Garden, Russian Academy of Sciences, Moscow, Russia \\ Correspondence should be addressed to E. V. Abakumov; e_abakumov@mail.ru
}

Received 1 July 2017; Revised 14 October 2017; Accepted 7 November 2017; Published 21 January 2018

Academic Editor: Rafael Clemente

Copyright (C) 2018 E. V. Abakumov et al. This is an open access article distributed under the Creative Commons Attribution License, which permits unrestricted use, distribution, and reproduction in any medium, provided the original work is properly cited.

\begin{abstract}
Humification is considered to be a global process that is implemented in soils and organic sediments and also in natural water and air. The term "suspended soils" has become increasingly common in recent years. Suspended soils are defined as the part of the organic matter that has not undergone the full decomposition process and has not turned into the humus of terrestrial soils. Suspended soils were shown to contain higher total nitrogen, phosphorus, and potassium contents than the forest soil, but the moisture content in suspended soils was significantly lower. Our study of the structural composition of humic substances in suspended soils was conducted with an aim of evaluating the humification rates and structural composition of humic acids in the suspended soil in tropical forests of South Vietnam. Soil samples from three selected areas were investigated: the soil under phorophytes (mineral soil presented by samples of topsoil of the typical dry savanna landscape) and two soils from epiphytous formations. Samples were collected from savanna-type sparse communities, located on oligotrophous plains in Phú Quốc Island (South Vietnam) in 2015. General properties of the soil and the elemental composition of suspended soils were determined, and the humic substance chemical composition was evaluated using solid state ${ }^{13} \mathrm{C}-\mathrm{NMR}$. Data obtained showed that the $\mathrm{pH}$ of the soils under phorophytes was higher than in the suspended soils; basal respiration did not tend to change indices between soils under phorophytes and suspended soils, but the suspended soil was less enriched by nitrogen than the soil under phorophytes. This can be related to the total amount of organic matter exposed to humification in various soils and to the presence of an essential portion of mineral particles in the soil under phorophytes. Data on elemental composition of the humic acids (HAs) indicated that one method of humification is implemented in all three soils that were investigated. The humic acids of the phorophyte soil showed the same content of aromatic fraction as the suspended soil. The most comparable soil type in terms of humic substance composition is Cambisols from humid forests of subboreal and subtropical zones. The humification process implemented in suspended soils showed the absence of mineral compounds or mineral fine earth, which indicated that humification in conditions of pure organic substrates can result in formation of deep humified organic matter, as shown by humic acids with an essential aromatic fraction content.
\end{abstract}

\section{Introduction}

Humification is considered to be a global process that is implemented in soils and organic sediments and also in natural water and air $[1,2]$. This universal process of transforming precursors of humification and polymerization of oligomer and monomer molecules into dark colored, high-molecularweight supermolecules has been described in terms of organic chemistry [3,4], environmental dynamics $[5,6]$, and various zonal soil dynamics [7-9]. In this context, investigation of the humification phenomenon in the suspended soil in tropical forests became an essential task that can be discussed as underestimated in humiomic science. The term "suspended soils" has become increasingly common in recent years. Suspended soils are defined as the part of the organic matter that has not undergone the full detritization and decomposition process and has not turned into humus in terrestrial soils [10]. Detritization is an important process in 
tropical forest ecosystems, providing a cycle of substances. The rate of organic matter decomposition is often dependent on climatic conditions such as temperature and precipitation [11], the quality of the decomposing material, and the species composition of the decomposer community. This process begins with aging of leaves, followed by leaf fall and sedimentation of litter in the forest [12]. However, if this sequence is not followed, organic matter does not enter the litter at the same time, but rather it accumulates on the surface of the forest obstacles. Such soils can exist for a long time in the form of undecomposed organic matter that is stabilized by various kinds of epiphytes, and the rate of organic matter decomposition in the canopy compared with that in the litter may change over time [13]. These soils are formed in places such as cracks, on branches, in tree bark, and in epiphytic associations, and they temporarily delay the organic matter from getting onto the surface of the soil [14]. They are also a substrate for vegetation, providing a greater variety of epiphytic vascular plants. The greatest variety of epiphytes is observed in the zone of accumulation of air litter compared with the crown and tree bark [15]. The roots of tropical epiphytes usually experience extreme fluctuations in the presence of moisture. They typically occur in small pockets of the soil where tree branches join trunks, in bark crevices on trunks, or on bare limbs, all of which have sites that dry more quickly than the soil of the forest floor [16]. Suspended soils in the forest canopy experience larger temperature and humidity changes than in the forest litter [17]. There are several adaptations through which the aerial roots of epiphytes can limit water loss to the dry air and still rapidly refill to permit water uptake during rainfall [18].

Suspended soils occur mainly in the tropical forests. According to the Food and Agricultural Organization (FAO), the area of tropical forests is estimated to be 1756.3 million hectares, which is about $37 \%$ of the land area of countries located in the tropical belt. Therefore, studying the structural and functional organization of these forest formations is important for a global quantitative assessment of their role in the deposition and emission of carbon [19]. Additionally, suspended soils are not considered to be part of special soil taxa in the world reference base of soil resources (WRB, 2014), and they are not discussed as possible sources of, and storage for, humic substances. They are also not included in the list of possible indicators for interpreting ecoclimatic conditions in tropical forests [20].

An important feature of tropical forests and monsoons, in particular, is associated with the inherent specificity of the substance cycle. They significantly exceed other ecosystems in the intensity with which they bind carbon and other biogenic chemical elements (including that in the organic mass). The cycles here are so intense and closed that the conservation of carbon in detritus, humus, and peat accumulation is insignificant. In the long term, formation and decomposition of organic matter, and thus absorption and release of carbon dioxide, are balanced. In contrast to tropical forests, carbon is preserved for a longer time in nutrient matter in the form of forest litter, humus, and peat in boreal (northern) forests [21].

The tier structure of monsoon forests is distinctive. Herbaceous and shrubby tiers are significantly reduced because of a lack of light. However, the upper tiers are highly developed, having a complex spatial structure and huge ecological capacity. In addition to the trees, there are abundant lianas and epiphytes, clusters of hanging soil and litter, and even a multitude of microvagos with a rich and specific microworld. In this complex mosaic of microbiotopes, the bulk of the animal diversity is concentrated [22]. The nature of the "air" litter, its accumulation, formation, and subsequent transformation depend on the amount of litter, its composition, time of arrival, geographic conditions, species composition of forest-forming species, age and stratification of the plantation, the closeness of forest canopy, and development of soil biota participating in the decomposition of litter [23]. Additionally, the composition of the epiphytes depends on the substrate (bark) characteristics, which are correlated with the characteristics of terrestrial soils. The mechanisms of connection between the soil and bark chemistry are unknown, but several explanations can be postulated. Of these, an impact of the soil on the bark through transportation of nutrients from the tree roots to the bark seems most likely. Because bark chemical factors are important for epiphytic species, soil properties might affect the composition of the epiphytic vegetation [24].

It was shown previously that suspended soils contain a higher content of total nitrogen, phosphorus, and potassium and have a significantly lower moisture content compared with the forest soil. Higher levels of nutrients in the canopy system are explained by differences in the intake of coarsegrained wood waste (but not foliar litter) combined with a decrease in nutrient uptake by roots and less mobilization of nutrients by detritus and fungi [13]. The limited amount of humidity in the canopy system may have contributed to a reduction in weight loss, as well as a lower abundance and richness of oribatide mites, in garbage bags placed on the suspended soil under the canopy.

A study of the structural composition of humic substances in suspended soils has not previously been performed.

Thus, our study aimed to evaluate the humification rates and structural composition of humic acids in the suspended soil in the tropical forest of South Vietnam.

The objectives of this study were as follows:

(i) To characterize general soil properties and elemental composition of suspended soils

(ii) To evaluate humic substance chemical composition using solid state ${ }^{13} \mathrm{C}-\mathrm{NMR}$

\section{Materials and Methods}

2.1. Study Sites. The study site was located on Phú Quốc Island (South Vietnam) in 2015. This island is situated close to the Cambodia coast and encompassed a total area of about $589 \mathrm{~km}^{2}$ (Figure 1). The main area of the island is occupied by ridges that are covered by dense forests. The highest ridge peak is Chua mountain, which is $603 \mathrm{~m}$ above sea level.

The climate is subequatorial and humid throughout the year, and the relatively dry period is short (January-February). Annual precipitation is $2879 \mathrm{~mm}$, while on some northernmost ridges this value reaches $4000 \mathrm{~mm}$. April and May are the 


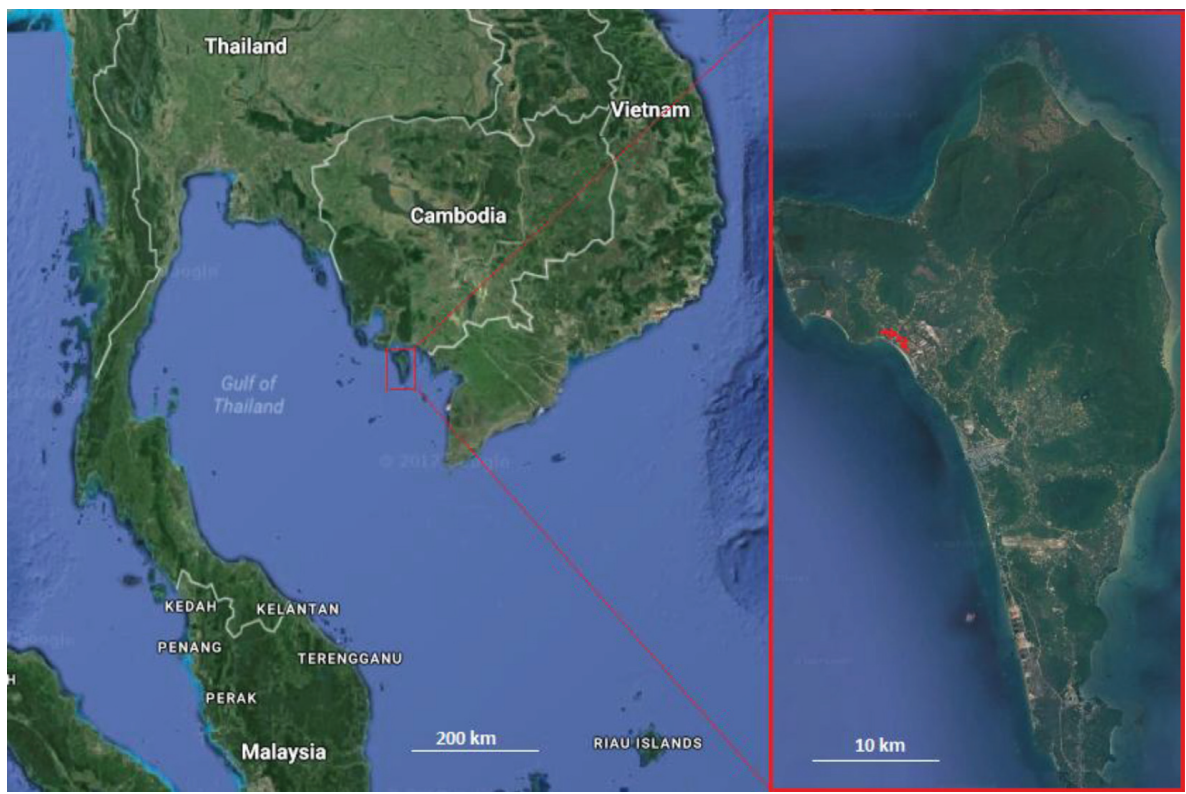

FIgure 1: Study site location, Phú Quốc Island.

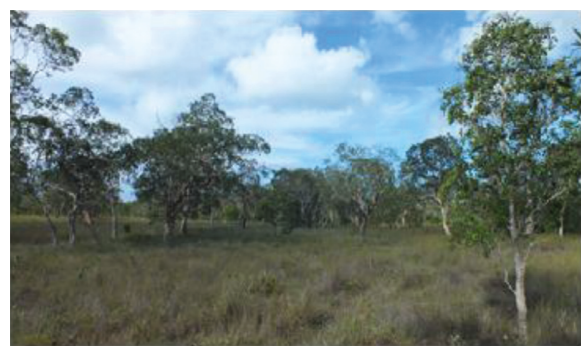

(a)

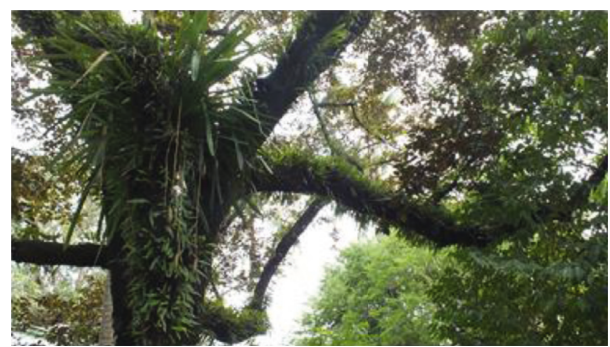

(b)

Figure 2: Dry savanna environment (a) and phorophyte with epiphyte soil in dry savanna (b).

hottest months, with a maximum temperature of about $35^{\circ} \mathrm{C}$. The national park is situated in the northern part of the island. The main difference between the island and the main part of South Vietnam is the increased density of the forest canopy and the total area, which is occupied by forest types of environments. We took samples and investigated three soil samples (Figures 1 and 2): (1) the soil under phorophytes, which is the mineral soil represented by samples of the topsoil from the typical dry savanna landscape, and (2) and (3) soil samples of epiphytous formations from the same dry savanna formation. Samples of the savanna-type soil were collected in sparse communities located on oligotrophous plains. Samples of suspended soils with a total mass of about $100 \mathrm{~g}$ were collected with the fixation of the epiphyte and phorophyte plant species. Additionally, the soil from under phorophytes was also collected. Samples were air-dried. There are six species of epiphytes that actively take part in the formation of the suspended soils: two orchids (Acriopsis sp. and Cymbidium fynlaisonianum) and four ferns (Drynaria sparsisora, Platycerium grande, Pyrrosia adnascens, and Pyrrosia longifolia). Dry savannas, located close to the Cua-Can settlement, form a narrow environment that is oriented along the sea shore. This ecosystem is dominated by Dipterocarpus aff., tuberculatus
Roxb., and Dillenia obovata (Blume) Hoogland, which is characterized by rough bark and is favorable for epiphyte inhabitation. The tree stands were relatively sparse with weakly developed grass cover and well-presented areas of sand with no vegetation. Many of the trees were colonized by vascular plants from the semiparasitic Loranthaceae family. In more humid locations (close to the streams and ponds), the fern creepers such as Lygodium sp. and Stenochlaena palustris (Burm. f.) Bedd, as well as Dicranopteris linearis (Burm. f.) Underw. (Gleicheniaceae), became more typical. The dry savanna is next to the coast and it is separated from the coast line by a series of sandy dunes, which are colonized by prickly bush vegetation and representatives of the species Ipomoea pescaprae (L.) R. Br and Casuarina sp. Single trees (Calophyllum inophyllum L. and Terminalia catappa L.) are also present. The dune surface is also covered by tuberous aroides of the Amorphophallus spp.

2.2. Laboratory Methods. All chemical soil parameters were studied using the fine soil that was passed through a $2 \mathrm{~mm}$ sieve. Total organic carbon and nitrogen content were determined using a $\mathrm{C}-\mathrm{H}-\mathrm{N}$ analyzer. The $\mathrm{pH}$ values were 
TABLE 1: General characteristics of soils.

\begin{tabular}{lccccccc}
\hline Sample & $\mathrm{pH}$ in water & $\mathrm{pH}$ in salt & Skeletol fraction (\%) & Basal respiration $\left(\mathrm{mgCO}_{2} / \mathrm{g}\right.$ soil in $\left.\mathrm{h}\right)$ & Carbon (\%) & Nitrogen (\%) & $\mathrm{C} / \mathrm{N}$ \\
\hline 1 & 6.33 & 5.16 & 0.08 & 434.61 & 4.00 & 0.23 & 17.39 \\
2 & 5.47 & 3.55 & 8.7 & 779.43 & 44.38 & 1.85 & 23.98 \\
3 & 5.48 & 3.69 & 18 & 352.00 & 41.45 & 1.34 & 30.93 \\
\hline
\end{tabular}

TABle 2: Elemental composition of the HAs, extracted from soils.

\begin{tabular}{lccccccc}
\hline Sample & $\mathrm{C}(\%)$ & $\mathrm{H}(\%)$ & $\mathrm{N}(\%)$ & $\mathrm{O}(\%)$ & $\mathrm{C} / \mathrm{N}$ & $\mathrm{H} / \mathrm{C}$ & $\mathrm{O} / \mathrm{C}$ \\
\hline 1 & 49.17 & 5.11 & 3.30 & 37.42 & 14.90 & 0.10 & 0.76 \\
2 & 48.77 & 5.40 & 3.58 & 37.25 & 13.62 & 0.11 & 0.76 \\
3 & 49.52 & 5.26 & 3.08 & 37.14 & 16.07 & 0.10 & 0.75 \\
\hline
\end{tabular}

TABLE 3: Carbon species in humic acids of soils investigated.

\begin{tabular}{lcccccccccccccc}
\hline \multirow{2}{*}{ Sample } & \multicolumn{10}{c}{ Chemical shifts values $(\mathrm{ppm})$ and related carbon species content } \\
& $190-170$ & $170-150$ & $150-135$ & $135-108$ & $108-100$ & $100-70$ & $70-50$ & $50-32$ & $32-27$ & $27-10$ & $10-0$ & Aromatic & Aliphatic \\
\hline 1 & 9.00 & 8.90 & 6.64 & 17.25 & 4.16 & 14.81 & 13.32 & 12.15 & 4.99 & 8.41 & 0.38 & 0.36 & 0.64 \\
2 & 9.01 & 8.01 & 6.15 & 15.22 & 4.33 & 15.33 & 15.35 & 12.17 & 5.06 & 8.99 & 0.39 & 0.33 & 0.67 \\
3 & 8.33 & 8.60 & 6.68 & 16.30 & 4.16 & 15.23 & 14.94 & 12.29 & 5.00 & 8.17 & 0.31 & 0.34 & 0.66 \\
Average & 8.78 & 8.50 & 6.49 & 16.25 & 4.21 & 15.12 & 14.54 & 12.20 & 5.01 & 8.52 & 0.36 & 0.34 & 0.66 \\
\hline
\end{tabular}

determined using routine methods in a water suspension. The main physicochemical parameters of the suspended soils were estimated as follows: $\mathrm{pH}$ in water, $\mathrm{pH}$ in salt, total organic carbon (\%), skeleton fraction (\%), and basal respiration $\left(\mathrm{mgCO}_{2} / \mathrm{g}\right.$ soil/h). Basal respiration of soils was determined by incubating soil material in a closed chamber for 10 days without adding nutrient substrates at a temperature of $22^{\circ} \mathrm{C}$ and a humidity of about $60 \%$. The liberated carbon dioxide was captured with a solution of $\mathrm{NaOH}$. The amount of carbon dioxide released was determined by titrating the alkali residues at the end of the experiment [25].

HAs were extracted from each soil sample using a previously published procedure [26-28]. Briefly, HAs were extracted using $0.1 \mathrm{M} \mathrm{NaOH}$ (soil/solution ratio $1: 10$ ) under nitrogen gas. After shaking for $24 \mathrm{~h}$, the alkaline supernatant was separated from the soil residue by centrifugation at $1516 \times \mathrm{g}$ for $20 \mathrm{~min}$, and it was then acidified to $\mathrm{pH} 1 \mathrm{using}$ $6 \mathrm{M} \mathrm{HCl}$ to induce HA precipitation. The supernatant, which contained the fulvic acids FAs, was separated from the precipitate (HAs) by centrifugation at $1516 \times \mathrm{g}$ for $15 \mathrm{~min}$. The HAs were then redissolved in $0.1 \mathrm{M} \mathrm{NaOH}$ and shaken for $4 \mathrm{~h}$ under nitrogen before the suspended solids were removed by centrifugation. The HA solution was acidified again with $6 \mathrm{M} \mathrm{HCl}$ to $\mathrm{pH} 1$, and the HAs were separated by centrifugation. This procedure was used in previous studies for characterization of soils of various environments $[29,30]$. The HAs were demineralized by shaking overnight in $0.1 \mathrm{M} \mathrm{HCl} / 0.3 \mathrm{M} \mathrm{HF}$ (solid/solution ratio $1: 1$ ) and then repeatedly washed with deionized water until $\mathrm{pH} 3$ was reached; they were then freeze-dried [31-33].

HAs were characterized for their elemental composition (C, N, and H) using a Euro EA3028-HT analyzer. Data were corrected for water and ash content. Oxygen content was calculated by the difference between samples, taking into account the ash content. The elemental ratios reported in this paper are based on weight. HAs were characterized for their elemental composition (C, N, H, and S) using a CHN 185BHewlett Packard analyzer. Data were corrected for water and ash content. Investigations were performed using an NMR spectrometer (Bruker Avance III WB 400; $100.64 \mathrm{MHz}$ for ${ }^{13} \mathrm{C}$ and $400.23 \mathrm{MHz}$ for ${ }^{1} \mathrm{H}$ ). Solid-phase samples were placed in a $4 \mathrm{~mm}$ zirconium oxide rotor and spun at a frequency of $12.5 \mathrm{kHz}$ at the magic angle; for acquisition of ${ }^{13} \mathrm{C}$ spectra, cross-polarization sequence of excitation pulses was used (CP/MAS). The contact time was $2 \mathrm{~ms}$, the delay time was $1 \mathrm{~s}$, and the number of scans was 50,000.

Groups of structural compounds were identified using the following chemical shifts values: 190-170 ppm for the carboxyl group and amidic carbonyl; 170-150 ppm for the aromatic $C$ of phenols and phenol esters; $150-135$ ppm for the alkylaromatics; $135-108$ ppm for the protonized aromatic carbon, bridgehead C; $108-70$ ppm for the cellulose anomeric carbon and hemiacetal carbon; 70-50 ppm for the resonance region of $\mathrm{C}-\mathrm{H}$ bonds, secondary alcohols, and other carbon atoms bound to oxygen; 50-32 ppm for the methyl group resonance region of aliphatic and aromatic ethyl ethers, amino acid carbons, and methyl esters of carboxylic groups; $32-27 \mathrm{ppm}$ for the resonance region of quaternary carbon and $\mathrm{CH}$ carbons; $27-10 \mathrm{ppm}$ for the resonance region of $\mathrm{CH}_{2}$ alkyl structures in transconformation; and $10-0 \mathrm{ppm}$ for the resonance region of alkyl methyls and $\mathrm{CH}_{2}$ units [33-37].

The aliphaticity degree was calculated as the sum of intensities in chemical shift area $0-105 \mathrm{ppm}$, while the aromaticity degree was calculated as the sum of the peaks in 105-165 ppm area [38-41]. 


\section{Results and Discussion}

General chemical characteristics of soils are shown in Table 1. The $\mathrm{pH}$ of the soils under phorophytes was higher. Humus in suspended soils had a very low $\mathrm{pH}$ compared with terrestrial soils, and the acidic nature of this substrate may have a profound effect on within-mat nutrient dynamics. For example, the lack of nitrification in canopy mats documented by Vance and Nadkarni [42] may be a result of the low $\mathrm{pH}$ of the crown humus, which is similar to other peat-dominated soils $[25,43]$. A greater amount of undecomposed organic matter, compared with the mineral part in suspended soils, causes a stronger acid reaction. This is because of the slow transformation of organic acids to humic substances. According to Bohlman et al. [17], the turnover time of detritus in the canopy has been documented as nearly twice as long as the litterfall on the forest floor. Dry conditions could affect the density, composition, and life cycles of organisms responsible for decomposition processes. The rapid loss of water depends on the structure and composition of suspended soils (fibrous and composed mainly of litter of bryophytes), as well as the lack of connection with mineral (moisture saturated) horizons. The suspended soil is also exposed to different microclimatic conditions compared with the terrestrial soil, which could explain the greater extremes of the moisture range. During the day, greater wind speeds, higher air temperatures and solar radiation, and lower humidity in the canopy promote more evaporation of water from the suspended soil compared with the terrestrial soil. Despite the differences in forest floor and canopy microclimate, differences in the temperatures of suspended and terrestrial soils are minor [17]. Basal respiration did not tend to change indices in soils under phorophytes or in suspended soils. The results showed a high level of microbial biomass activity, which is associated with a large amount of initial material in soil samples. The suspended soil is less enriched by nitrogen than soils under phorophytes. This can be related to the total amount of organic matter exposed to humification in various soils and to the presence of an essential portion of mineral particles in the soil from under phorophytes.

To characterize the changes in HA structure, the degree of oxidation, calculated as the atomic ratio of oxygen to carbon $(\mathrm{O} / \mathrm{C})$, is of particular interest. Data on the elemental composition of humic acids in the suspended soil are listed in Table 2. Additionally, an important indicator is the hydrogen to carbon $(\mathrm{H} / \mathrm{C})$ ratio, characterizing the degree of aromaticity or unsaturation (at low values) or aliphatic structures (at high values). Aromatic or unsaturated fragments are predominated in the test samples $(\mathrm{H} / \mathrm{C}<1)$. A more reliable indicator, correlating with aromaticity, is $\mathrm{U}$-unsaturation, because the $\mathrm{H} / \mathrm{C}$ ratio takes into account the presence of multiple carbon-heteroatom bonds in the composition of functional groups [44].

When the nitrogen content in the investigated HA was analyzed, the requirements for the diagnostic features of the HA according to Orlov [45] were satisfied; these diagnostic features state that the nitrogen content should be from 3 to 6 gravimetric percent. Humification of plant residues caused

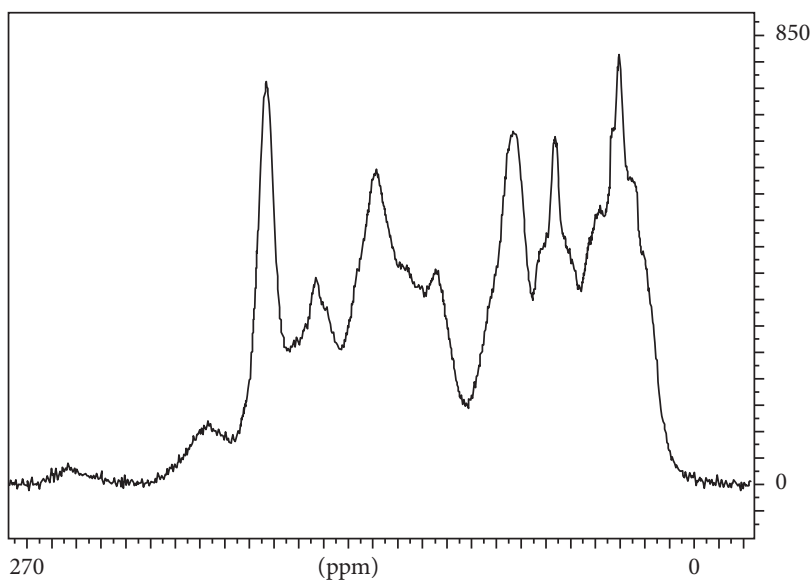

(a)

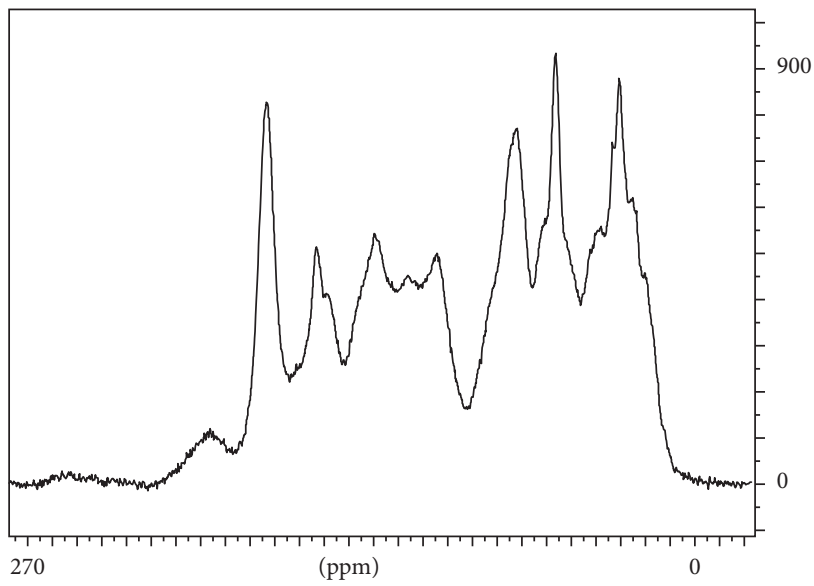

(b)

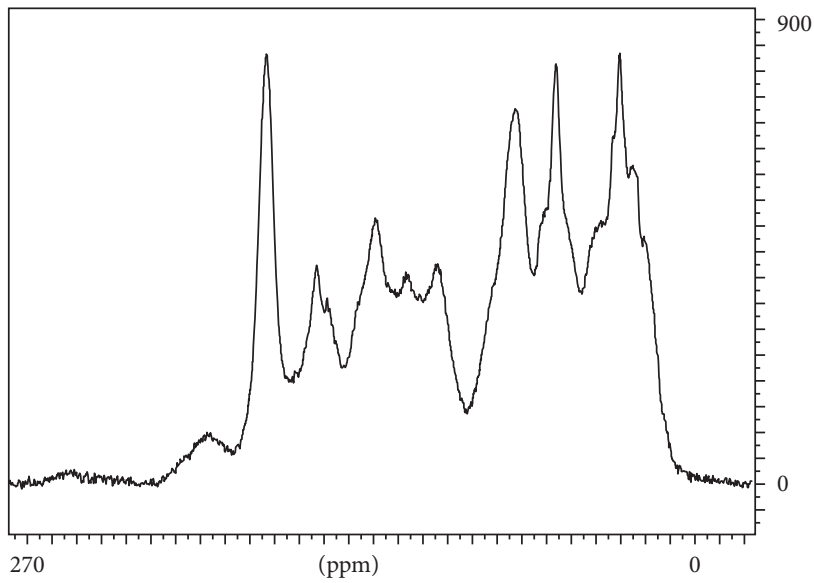

(c)

FIGURE 3: ${ }^{13} \mathrm{C}-\mathrm{NMR}$ spectras of humic acids, extracted from suspended (a) and phorophyte (b and c) soils.

a decrease in both the $\mathrm{H} / \mathrm{C}$ and $\mathrm{O} / \mathrm{C}$ ratios. Thus, these values are typical for the average standard HAs [46, 47]. Data on elemental composition of the HAs indicate that one method of humification is implemented in all three soils investigated.

Data on humic acid structural composition and carbon species content are presented in Table 3 and in Figure 3. The 
most evident was that humic acids, extracted from all suspended soils, are fairly equal in terms of carbon species distribution and main fraction content. The soil under phorophytes is characterized by the same aromatic fraction content. In both phorophyte and suspended soils, the microcosm for humification is aerated enough for relatively intensive humification. If one compares the soils investigated with soils of various natural environments, soils investigated will present an intermediate version between soils with a large degree and small degree of humification. Aromatic compound content is higher than in tundra or taiga soils, but lower than in Mollisols [3, 8, 38, 46]. The most comparable soil type in terms of humic substance composition is the Cambisol soil from humid forests in subboreal and subtropical zones. This type of ratio between aromatic and aliphatic compounds is typical for the soil with prevailing humic conditions that are interrupted from time to time by dry periods [48]. The humification process is implemented in suspended soils with evident absence of mineral compounds or mineral fine earth, which indicates that humification in conditions of pure organic substrates can result in formation of deep humified organic matter that is represented by humic acids with an essential aromatic fraction content.

\section{Conclusions}

A study of the structural composition of humic substances in suspended soils was performed for the first time. Samples included the soil from under phorophytes (the mineral soil represented by samples of the topsoil from the typical landscape of a dry savanna) and two soils from epiphytous formations from a savanna-type in sparse communities, which are located on oligotrophous plains in Phú Quốc Island (South Vietnam). Samples were collected in 2015. Our results show that the $\mathrm{pH}$ of the soils under phorophytes is higher, which is consistent with data from other studies, and that it depends on a greater amount of undecomposed organic matter compared with the mineral part in suspended soils, which causes a stronger acid reaction. This is because of the slow transformation of organic acids to humic substances. A greater amount of undecomposed organic matter, compared with the mineral part in suspended soils, causes a stronger acid reaction. Additionally, suspended soils are less enriched by nitrogen than soils under phorophytes. Basal respiration, which indicates a level of activity of microbial biomass, did not tend to change in soils under phorophytes compared with suspended soils. In all three soils investigated, one method of humification and the nitrogen content satisfy the requirements for HA diagnostic features. The structural composition of the humic acids extracted from all suspended soils is almost equal in terms of carbon species distribution and main fraction content. The soil under phorophytes is characterized by a larger aromatic fraction and smaller portion of aliphatic groups, and it was shown to have an $\mathrm{H} / \mathrm{C}$ ratio $<1$. This can be explained by the higher degree of humification in more aerated pedoenvironments of the soil under phorophytes where organic remnants are surrounded by minerals. The aromatic compound's content is higher than in tundra or taiga soils, but lower than in mollisols. Soils that we investigated were an intermediate version between soils with a large amount and soils with a small amount of humification. The most comparable soil type in terms of humic substances composition is Cambisols from the humid forests in subboreal and subtropical zones. We showed, for the first time, that formation of deep humified organic matter with an essential aromatic fraction content can be implemented during the humification process in suspended soils with evident absence of mineral compounds or mineral fine earth in conditions of pure organic substrates.

\section{Conflicts of Interest}

The authors declare that they have no conflicts of interest.

\section{Acknowledgments}

This work was partially supported by the Russian Foundation for Basic Research (Project no. 15-29-02525 (expedition and sample collection) and Project no. 18-04-00677 (routine chemical analyses)) and the Russian Scientific Foundation (Project no. 17-16-01030, "Soil biota dynamics in chronoseries of posttechnogenic landscapes: analyses of soilecological effectiveness of ecosystems restoration" (microbiological analyses and 13C-NMR spectroscopy)). Analytical analyses were performed at the Centre for Magnetic Resonance and at the Centre for Chemical Analysis and Materials Research of Research Park of St. Petersburg State University.

\section{References}

[1] C. P. Morley, K. A. Mainwaring, S. H. Doerr, P. Douglas, C. T. Llewellyn, and L. W. Dekker, "Organic compounds at different depths in a sandy soil and their role in water repellency," Australian Journal of Soil Research, vol. 43, no. 3, pp. 239-249, 2005.

[2] K. J. Wang, "Characterization of humic substances and non-ideal phenanthrene sorption as affected by clay-humic interactions," Ph.D. dissertation, University of Massachusetts, Amherst, MA, USA, 2005, http://humic-substances.org/ bibliography/.

[3] I. V. Perminova, L. A. Karpiouk, S. A. Ponomarenko et al., "Controlling aqueous sorption of humic substances on silica gel by directed alkoxysilyl-derivatization of their functionalities," Colloids and Surfaces A: Physicochemical and Engineering Aspects, vol. 396, pp. 224-232, 2012.

[4] F. Sannino, A. Nuzzo, V. Ventorino, O. Pepe, and A. Piccolo, "Effective degradation of organic pollutants in aqueous media by microbial strains isolated from soil of a contaminated industrial site," Chemical and Biological Technologies in Agriculture, vol. 3, no. 1, 9 pages, 2016.

[5] G. Almendros, P. Tinoco, J.-M. De la Rosa, H. Knicker, J.-A. González-Pérez, and F. J. González-Vila, "Selective effects of forest fires on the structural domains of soil humic acids as shown by dipolar dephasing ${ }^{13} \mathrm{C}$ NMR and graphicalstatistical analysis of pyrolysis compounds," Journal of Soils and Sediments, vol. 16, p. 10, 2016.

[6] M. López-Martín, M. Velasco-Molina, and H. Knicker, "Variability of the quality and quantity of organic matter in 
soil affected by multiple wildfires," Journal of Soils and Sediments, vol. 16, no. 2, pp. 360-370, 2016.

[7] E. D. Lodygin and V. A. Beznosikov, "The molecular structure and elemental composition of humic substances from Albeluvisols," Chemistry and Ecology, vol. 26, no. 2, pp. 87-95, 2010.

[8] E. D. Lodygin, V. A. Beznosikov, and R. S. Vasilevich, "Molecular composition of humic substances in tundra soils $\left({ }^{13}\right.$ C-NMR spectroscopic study)," Eurasian Soil Science, vol. 47, no. 5, pp. 400-406, 2014.

[9] O. Trubetskaya, O. Trubetskoj, and C. Richard, "Hydrophobicity of electrophoretic fractions of different soil humic acids," Journal of Soils and Sediments, vol. 14, no. 2, pp. 292-297, 2014.

[10] P. Shaw, "The use of inert pads to study Collembola of suspended soils," Soil organisms, vol. 85, no. 1, pp. 69-74, 2013.

[11] J. A. Trofymow, T. R. Moore, B. Titus et al., "Rates of litter decomposition after six years in Canadian forests: influence of litter quality and climate," Canadian Journal of Forest Research, vol. 32, no. 5, pp. 789-804, 2002.

[12] R. Hempfling, N. Simmleit, and H.-R. Schulten, "Characterization and chemodynamics of plant constituents during maturation, senescence and humus genesis in spruce ecosystems," Biogeochemistry, vol. 13, no. 1, pp. 27-60, 1991.

[13] Z. Lindo and N. N. Winchester, "Oribatid mite communities and foliar litter decomposition in canopy suspended soils and forest floor habitats of western redcedar forests, Vancouver Island, Canada," Soil Biology and Biochemistry, vol. 39, no. 11, pp. 2957-2966, 2007.

[14] Z. Lindo and N. N. Winchester, "A comparison of microarthropod assemblages with emphasis on oribatid mites in canopy suspended soils and forest floors associated with ancient western redcedar trees," Pedobiologia, vol. 50, no. 1 , pp. 31-41, 2006.

[15] H. Steege and J. H. C. Cornelissen, "Distribution and ecology of vascular epiphytes in lowland rain forest of Guyana," Biotropica, vol. 21, no. 4, pp. 331-339, 1989.

[16] R. K. Antibus and P. Lesica, "Root surface acid phosphatase activities of vascular epiphytes of a Costa Rican rain forest," Plant and Soil, vol. 128, no. 2, pp. 233-240, 1990.

[17] S. A. Bohlman, T. J. Matelson, and N. M. Nadkarni, "Moisture and temperature patterns of canopy humus and forest floor soil of a montane cloud forest, Costa Rica," Biotropica, vol. 27, no. 1, pp. 13-19, 1995.

[18] G. B. North and P. S. Nobel, "Changes in root hydraulic conductivity for two tropical epiphytic cacti as soil moisture varies," American Journal of Botany, vol. 81, no. 1, pp. 46-53, 1994.

[19] K. A. Kalashnikova, Soil Micromycetes of Typical Forests of Southern Vietnam by the Example of National Parks Dong Nai, Bee Dup - Nui Ba, Chu Yang Sin and Lok Bak, MSU, Moscow, Russia, 2016, http://www.bio.msu.ru/dissertations/view.php? $\mathrm{ID}=748$, Russian.

[20] M. Richter, "Using epiphytes and soil temperatures for ecoclimatic interpretations in southern Ecuador," Erdkunde, vol. 57, no. 3, pp. 161-181, 2003.

[21] P. W. Richards, The Life of the Jungle, McGraw-Hill Companies, New York, NY, USA, 1970.

[22] T. L. Erwin, "Tropical forests: their richness in Coleoptera and other arthropod species," Coleopterists Bulletin, vol. 36, no. 1, pp. 74-75, 1982.

[23] L. G. Bogatyrev, "Litter formation is one of the most important processes in forest ecosystems," Pochvovedenie, no. 4, pp. 501-511, 1996, Russian.
[24] L. Gustafsson and I. Eriksson, "Factors of importance for the epiphytic vegetation of aspen Populus tremula with special emphasis on bark chemistry and soil chemistry," Journal of Applied Ecology, vol. 32, no. 2, pp. 412-424, 1995.

[25] A. K. Eskov, E. V. Abakumov, A. V. Tiunov et al., "Ageotropic aerial root-traps of nest epiphytes and their role in suspended soils forming," Journal of General Biology, vol. 78, no. 3, pp. 54-68, 2017.

[26] E. V. Abakumov, E. Lodygin, and V. M. Tomashunas, ${ }^{~}{ }^{13} \mathrm{C}$ NMR and ESR characterization of humic substances isolated from soils of two Siberian arctic islands," International Journal of Ecology, vol. 2015, Article ID 390591, 7 pages, 2015.

[27] V. A. Kholodov, A. I. Konstantinov, A. V. Kudryavtsev, and I. V. Perminova, "The structure of humic acids of zonal soils according to C-13 NMR spectroscopy data," Pochvovedenie, no. 9, pp. 1064-1073, 2011, Russian.

[28] M. Schnitzer, "Organic matter characterization," in Methods of Soil Analysis, B. Page, R. Miller, and D. Keeney, Eds., pp. 581-594, Soil Science Society of America, Madison, WI, USA, 1982.

[29] A. Lupachev, S. Gubin, and E. Abakumov, "The influence of cryogenic mass exchange on the composition and stabilization rate of soil organic matter in cryosols of the Kolyma Lowland (North Yakutia, Russia)," Geosciences, vol. 7, no. 24, p. 24, 2017.

[30] E. Abakumov, "Characterisation of humic acids, isolated from selected subantarctic soils by ${ }^{13} \mathrm{C}-\mathrm{NMR}$ spectroscopy," Czech Polar Reports, vol. 7, no. 1, pp. 1-10, 2017.

[31] M. A. Arshad, J. A. Ripmeester, and M. Schnitzer, “Attempts to improve solid state ${ }^{13} \mathrm{C}$ NMR spectra of whole mineral soils," Canadian Journal of Soil Science, vol. 68, no. 3, pp. 593-602, 1988.

[32] M. Schnitzer, "Soil organic matter-the next 75 years," Soil Science, vol. 151, no. 1, pp. 41-58, 1991.

[33] B. Chefetz, M. J. Salloum, A. P. Deshmukh, and P. G. Hatcher, "Structural components of humic acids as determined by chemical modifications and carbon-13 NMR, pyrolysis, and thermochemolysis-gas chromatography/mass spectrometry," Soil Science Society of America Journal, vol. 66, no. 4, pp. 1159-1171, 2002.

[34] S. N. Chukov, E. V. Abakumov, and V. M. Tomashunas, "Characterisation of humic acids isolated from Antarctic soils by ${ }^{13}$ C-NMR spectroscopy," Eurasian Soil Science, vol. 50, no. 1, pp. 30-33, 2017.

[35] K. H. Dai, C. E. Johnson, and C. T. Driscoll, "Organic matter chemistry and dynamics in clear-cut and unmanaged hardwood forest ecosystems," Biogeochemistry, vol. 54, no. 1, pp. 51-83, 2001.

[36] R. Frund, G. Guggenberger, and K. Haider, "Recent advances in the spectroscopic characterization of soil humic substances and their ecological relevance," Zeitschrift für Pflanzenernährung und Bodenkunde, vol. 157, no. 3, pp. 175-186, 1994.

[37] M. Gonzales-Perez, L. Martin-Neto, S.C. Saab et al., "Characterization of humic acids from a Brazilian oxisol under different tillage systems by EPR, ${ }^{13} \mathrm{C}$ NMR, FTIR and fluorescence spectroscopy," Geoderma, vol. 118, no. 3-4, pp. 181190, 2004.

[38] E. Ejarque and E. Abakumov, "Stability and biodegradability of organic matter from Arctic soils of Western Siberia: insights from ${ }^{13} \mathrm{C}-\mathrm{NMR}$ spectroscopy and elemental analysis," Solid Earth, vol. 7, no. 1, pp. 153-165, 2016.

[39] R. L. Malcolm, "Applications of solid-state ${ }^{13} \mathrm{C}$ NMR to geochemical studies of humic substances," Humic Substances II, pp. 340-372, J. Wiley, New York, NY, USA, 1989. 
[40] C. Keeleer, E. F. Kelly, and G. E. Maciel, "Chemical-structural information from solid-state ${ }^{13} \mathrm{C}$ NMR studies of a suite of humic materials form a lower montane forest soil, Colorado, USA," Geoderma, vol. 130, no. 1-2, pp. 124-140, 2006.

[41] A. J. Simpson and M. J. Simpson, "Nuclear magnetic resonance analysis of natural organic matter," in BiophysicoChemical Processes Involving Natural Nonliving Organic Matter in Environmental Systems, N. Senesi, B. Xing, and P. M. Huang, Eds., pp. 589-650, John Wiley \& Sons, Inc., Hoboken, NJ, USA, 2009.

[42] E. Vance and N. M. Nadkarni, "Microbial biomass and activity in canopy organic matter and the forest floor of a tropical cloud forest," Soil Biology and Biochemistry, vol. 22, no. 5, pp. 677-684, 1990.

[43] N. M. Nadkarni, D. Schaeferz, T. J. Matelson, and R. Solano, "Comparison of arboreal and terrestrial soil characteristics in a lower montane forest, Monteverde, Costa Rica," Pedobiologia, vol. 46, no. 1, pp. 24-33, 2002.

[44] E. M. Perdue, "Analytical constraints on the structural features of humic substances," Geochimica et Cosmochimica Acta, vol. 48, no. 7, pp. 1435-1442, 1984.

[45] D. S. Orlov, Humus Acids of Soils and General Theory of Humification, MSU, Moscow, Russia, 1990.

[46] E. D. Lodygin, Structural and Functional Parameters of Humus Substances of Taiga and Tundra Soils in the European Northeast of Russia, RSAU, Moscow, Russia, 2016, http://dlib. rsl.ru/viewer/01006652072\#?page=1, Russian.

[47] A. Savchenko, I. N. Korneeva, D. S. Goncharov, and E. A. Luksha, "The study of the structural features of humic substances," Modern Problems of Science and Education, no. 2, p. 624, 2014.

[48] N. Fujitake and M. Kawahigashi, ${ }^{13} \mathrm{C}$ NMR spectra and elemental composition of fractions with different particle sizes from an andosol humic acid," Soil Science and Plant Nutrition, vol. 45, no. 2, pp. 359-366, 1999. 

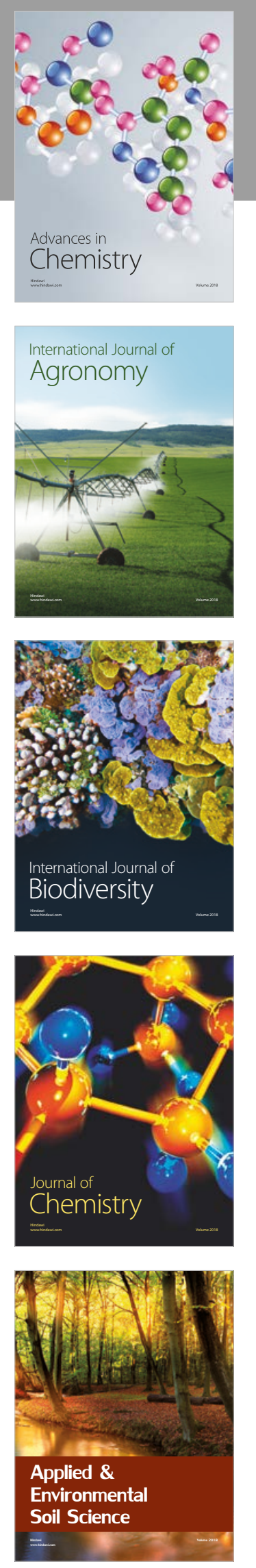

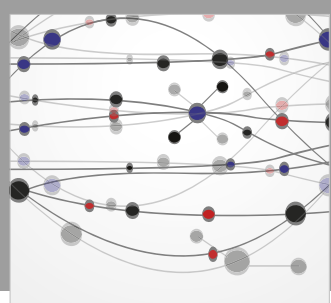

The Scientific World Journal

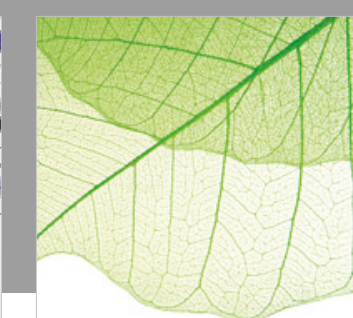

Journal of Botany

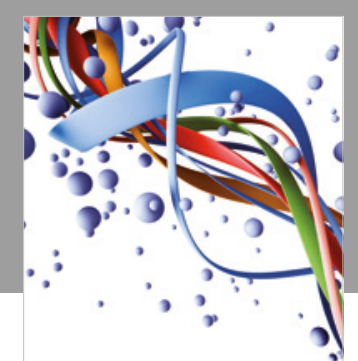

Scientifica

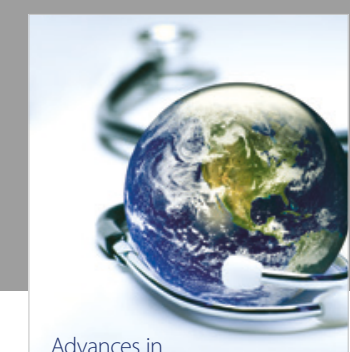

Public Health

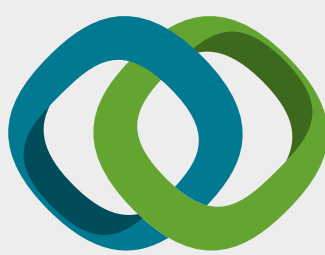

Hindawi

Submit your manuscripts at

www.hindawi.com
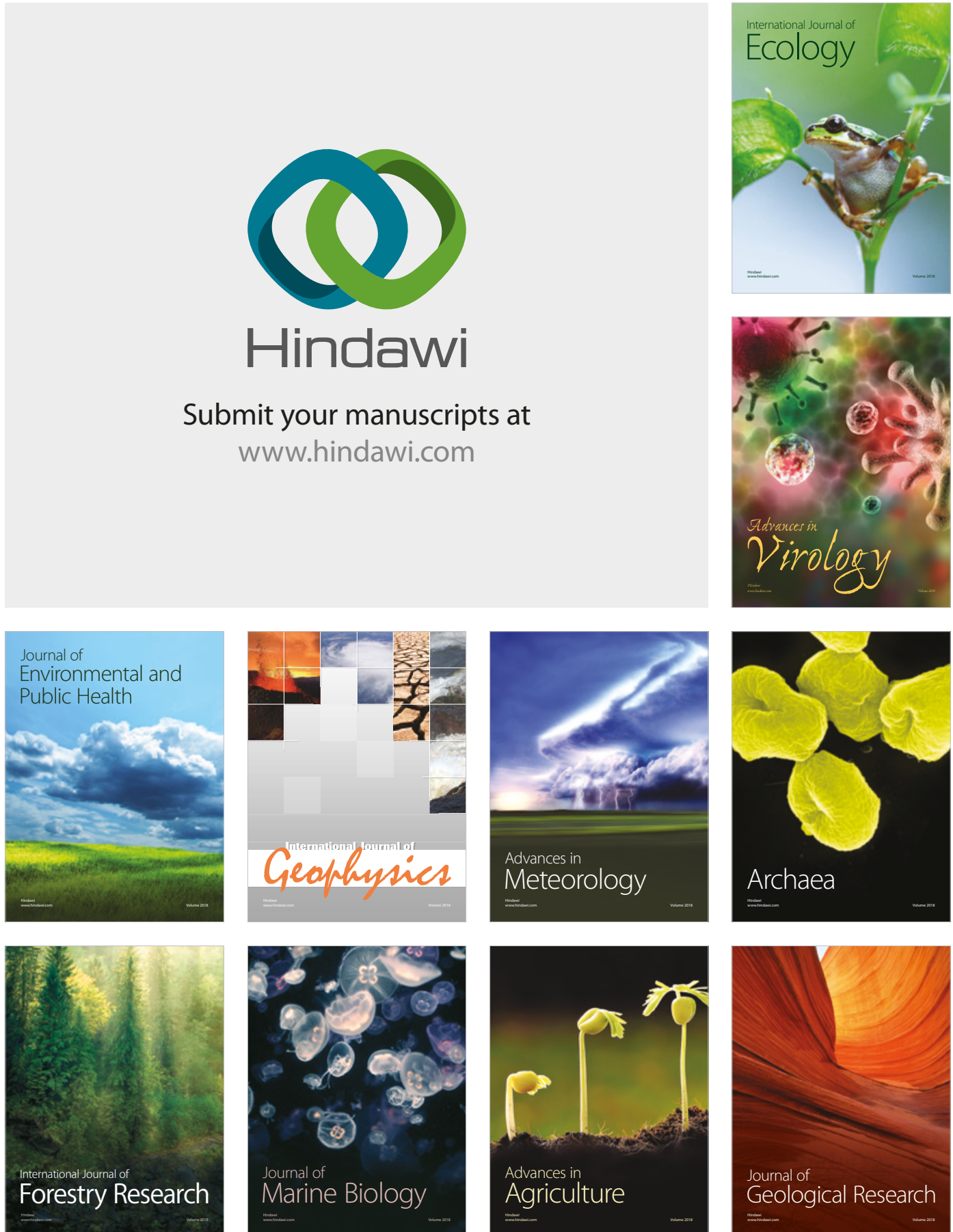

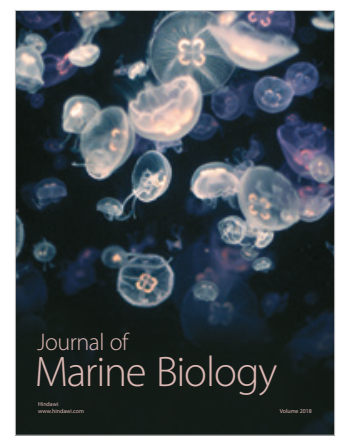

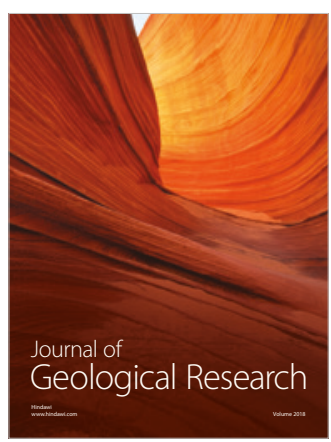

